\title{
TRADE LIBERALISATION AND HUMAN CAPITAL ADJUSTMENT
}

\author{
Rod Falvey, David Greenaway and Joana Silva \\ School of Economics and GEP, \\ University of Nottingham
}

Preliminary Draft: August 2007

\begin{abstract}
This paper highlights the way in which workers of different age and ability are affected by anticipated and unanticipated trade liberalisations. A two-factor (skilled and unskilled labour), two-sector Heckscher-Ohlin trade model is supplemented with a education sector which uses skilled labour and time to convert unskilled workers into skilled workers. A skilled worker's income depends on her ability, but all unskilled workers have the same income. Trade liberalisation in a relatively skilled labour abundant country increases the relative skilled wage and induces skill upgrading by the existing workforce. The younger and more able unskilled workers are most likely to upgrade. But not all upgraders are better off as a result of the liberalisation. The older and less able upgraders are likely to lose. For an anticipated liberalisation we show that the preferred upgrading strategies depend on a worker's ability and that much of the upgrading will take place before the liberalisation. This implies that some workers who would have upgraded had they anticipated the liberalisation will not if it is unanticipated, and that adjustment assistance that applies only to post-liberalisation upgraders will fail to compensate some losers and distort the upgrading decisions of others.
\end{abstract}

Keywords: International trade, Factor mobility, Labour market adjustment.

JEL Classification: F11, F16, J31, J62.

Address for correspondence: School of Economics, Sir Clive Granger Building, University of Nottingham, Nottingham, NG7 2RD. Tel + 44 (0)115 8466131. Fax: + 44 (0)115 9514159. E-mail: rod.falvey@nottingham.ac.uk. We are grateful to participants at the Royal Economic Society, Midwest International Economics, European Trade Study Group, European Economics and Finance Society Annual Meetings, and seminars at the University of Nottingham. Helpful comments on an earlier draft were received from Carl Davidson, Peter Wright and Richard Upward. Falvey and Greenaway acknowledge financial support from the Leverhulme Trust under Programme Grant F114/BE. Silva acknowledges financial support from Fundação para a Ciência e a Tecnologia (Grant No. SFRH/BD/13162/2003). 


\section{Introduction}

The links between product prices and factor returns are a key element of general equilibrium trade models. Interest in these links was heightened by the recent "trade and wages" debate, where lower prices of unskilled labour intensive products were put forward as one explanation for the decline in the relative wage of unskilled workers in advanced, skill-abundant countries. The underlying argument was based on the Stopler-Samuelson theorem which implies that trade liberalisation in unskilled labour scarce countries will lead to a fall in the relative price of unskilled labour intensive imports and thence a fall in the relative return to unskilled labour. The general conclusion of this debate seems to be that, while trade liberalisation may have been a contributing factor, technological change played the major role.

The changes in relative product prices that follow from trade liberalisation will also cause domestic resource reallocation towards those traded goods industries in which the country has a comparative advantage. These reallocations are an important source of the long run gains from trade. But in the short run they will involve adjustment costs, since resources cannot shift frictionlessly among activities. Adjusting workers in particular are likely to suffer periods of unemployment in the short-run, in addition to any longer run changes in their income streams. Although adjustment costs borne by workers are conventionally viewed as transitory and small relative to the benefits of trade liberalisation ${ }^{1}$, they are of concern for policy makers, not least because they represent the focal point of resistance to trade reform ${ }^{2}$.

Our aim in this paper is to extend the analysis of adjustment to trade liberalisation in a slightly different direction. Accepting that trade liberalisation in developed countries leads to an increase in the relative return to skilled labour, we explore the implications that this has for skill acquisition by the existing workforce. This is a relatively neglected aspect of adjustment. By treating workers within each skill group as homogeneous, most trade models implicitly assume all skilled and unskilled workers are affected equally. The changes in relative factor returns will cause some currently unskilled

\footnotetext{
1 This, for example, is the conclusion reached by Matusz and Tarr (2002) in a recent survey of evidence.

${ }^{2}$ The issues raised by short run adjustment costs have received some attention in the literature. See Davidson and Matusz (?) 
workers to rethink and reverse their decision to stay unskilled. The adjustment process that this induces begins immediately, but may not be completed until long after the short run frictions have been overcome. Worker characteristics, particularly age and ability, will be crucial in determining their decisions, and our paper highlights the way in which workers of different age and ability are affected by a trade expansion.

Our model modifies and extends earlier work by Findlay and Kierzkowski (1983) [FK] and Borsook (1986). We consider a small economy which consists of a manufacturing (traded goods) and an educational sector. The manufacturing sector is Heckscher Ohlin in structure and produces two traded goods using the services of skilled and unskilled labour. Unskilled workers enter the labour force without training. Education transforms unskilled individuals into skilled workers but takes time and resources ${ }^{3}$. We assume individuals differ in their (exogenous) ability level and, while the income of the unskilled is independent of their ability, more able skilled workers earn a proportionately higher income. Following Becker (1964 and 1993), Becker and Chiswick (1966) and Mincer (1974 and 1993) we model the educational investment decision accounting for the relationship between earning profiles, ability and age. In contrast to previous models we allow individuals to change labour status at any time in their working lives. The decision to enter the labour market as unskilled can be reversed later through schooling. The return to education is an increasing function of ability and youth. Given relative product prices, all individuals with ability above an endogenous threshold will become skilled. A trade liberalisation changes this steady

\footnotetext{
${ }^{3} \mathrm{FK}$ and Borsook assume the economy is endowed with a fixed stock of educational capital. In the FK model all individuals are ex ante identical, and the productivity of those that choose to become skilled is positively related to the capital/student ratio at the time they are educated. But in a steady state all skilled workers are identical. Borsook assumes, as we do, an exogenous distribution of individual ability. His main concern is the link between ability and the amount of schooling undertaken by individuals of different ability. While the length of the time spent in school is fixed, more able students receive a more intensive education, because the optimal capital/student ratio is increasing in ability. Earnings differentials then reflect the interaction of ability and schooling and not just schooling alone. In both of these models the relative stock of educational capital is an important determinant of the pattern of trade. We simplify the educational process by assuming that skilled labour (staff) rather than some exogenously given educational capital is the educational input (besides students) and there is a fixed staff/student ratio. Since our educational process has the same length and skilled labour input for all students, regardless of ability, we assume that their productivity as skilled workers depends only on their inherent ability. Dinopoulos and Segerstrom (1999) make a similar assumption, but in their case schooling takes time only. In our case the trade pattern will be determined by differences in the length of working lives, birth rates and the efficiency of the educational sector.
} 
state threshold and affects relative factor supplies and hence outputs in the long run. While we also consider these long run changes, which are the main focus of FK and Borsook, our main concern is with the medium run effects on the skill composition of the workforce existing at the time the liberalisation occurs or is announced.

Two key simplifying assumptions are worth reiterating upfront. First, we abstract completely from the short run frictional costs that are the focus of much of the adjustment literature. The movement of skilled and unskilled workers between production activities is assumed to be instantaneous and costless. This simplification allows us to highlight the medium run adjustment through skill upgrading by the existing workforce that has been largely neglected to date. Second, the HO structure implies that, as long as a country's manufacturing sector is non-specialised, factor returns depend only on product prices. In particular factor returns are constant throughout the adjustment process, so that workers' skill upgrading decisions are based on fixed and known future earnings. It should be emphasised that these assumptions are made for simplification only. Their relaxation will greatly complicate the analysis but should not invalidate the general results.

In outline the remainder of the paper is as follows. The next section sets out the model and determines the long run equilibrium supplies of skilled and unskilled labour. Section 3 then considers the medium and long term effects of an unanticipated trade liberalisation in a relatively skill abundant country. The increase in the relative return to skilled labour leads to some skill upgrading by the existing workforce. In each ability cohort we can determine an upgrading age cutoff, with younger workers upgrading and older workers remaining unskilled. The higher the ability level, the higher the age cutoff. But not all upgraders gain from the liberalisation, and for each ability cohort we can also determine an analogous gaining age cutoff, which is lower than the corresponding upgrading cutoff. Thus in any given ability cohort older upgraders tend to lose and younger upgraders to gain from the liberalisation. The dynamic path of adjustment of factor supplies is also illustrated.

The effects of an announced liberalisation (to take place at a known future date) are then derived in Section 4. Here our main concern is the pattern of upgrading by the workforce existing at the time of the announcement. Interestingly, for those 
who decide to upgrade, the optimal timing of the upgrading depends only on ability. Upgraders fall into three ability categories. The highest ability upgraders will do so immediately after the announcement. The next highest group will upgrade immediately before the liberalisation and the final group immediately after. The significance of this is that much of the medium term adjustment (upgrading) to an announced liberalisation by the existing workforce will occur before the liberalisation takes place. The differences in the patterns of upgrading between anticipated and unanticipated liberalisations are then exploited to illustrate patterns of regrets and reversals in Section 5. Specifically we can identify which workers, when faced with an unanticipated liberalisation, would claim "if I had known that was going to happen I would have acted differently". While such "regrets" are not an adjustment cost, they will condition an individual's attitudes to the liberalisation. Again it is older and less able workers that are most likely to regret their decision to remain unskilled without finding it worthwhile to reverse it. The more able workers, who still upgrade, will also regret not having done so earlier.

Section 6 briefly highlights two implications of our analysis for the design of programs of adjustment assistance. The first is to note that those undertaking adjustment (the upgraders) are a mixture of gainers and losers from the liberalisation. Any given age cohort contains both, depending on the upgrader's ability. Since the latter is likely to be unobservable, it will be difficult to target the assistance at losers. The second implication is that if the liberalisation is anticipated much of the upgrading will (and should) take place before it occurs. But if assistance is only provided post-liberalisation then early upgraders will not be covered. More importantly the decision on when to upgrade will be distorted towards the post-liberalisation. The final section concludes.

\section{The Model}

\subsection{Technology and factor prices}

Consider an economy with a manufacturing sector producing two tradable goods (1 and 2), using two factors (unskilled labour $(L)$ and skilled labour ( $S$ in efficiency units)) under standard constant returns to scale technologies. Factor services are assumed to be homogeneous and costlessly mobile between industries, implying that factor returns per efficiency unit $\left(\mathrm{W}_{\mathrm{L}}\right.$ and $\left.\mathrm{W}_{\mathrm{S}}\right)$ are common across industries. With perfectly 
competitive markets for goods and factors and assuming incomplete specialization, in the manufacturing sector in equilibrium the competitive profit conditions imply that

$$
P_{j}=a_{L j} W_{L}+a_{S j} W_{S}
$$

where $P_{j}$ is the price of output $j(j=1,2) ; a_{L j}$ and $a_{S j}$ are, respectively, the equilibrium requirement of unskilled and skilled labour per-unit of output $j$. Relative product prices determine factor returns, given the manufacturing technology.

Skilled labour is also employed in the education sector, which turns unskilled into skilled workers, a process that takes $E$ time periods and requires the services of $\beta$ units of skilled labour per student. The quantity of skilled labour services available for use in manufacturing $\left(S_{M}\right)$ then depends on the quantity of skilled labour services allocated to education $\left(S_{E}\right)$. If $X_{E}$ is the number of students, then the amount of skilled labour allocated to education is $\beta X_{E}$. Assuming full employment:

$$
\begin{aligned}
& L=L_{1}+L_{2}=a_{L 1} X_{1}+a_{L 2} X_{2} \\
& S=S_{M}+S_{E}=\left(S_{1}+S_{2}\right)+S_{E}=\left(a_{S 1} X_{1}+a_{S 2} X_{2}\right)+\beta X_{E}
\end{aligned}
$$

where $X_{j}$ denotes the output of good j. Finally, assume that at any common factor prices,

$$
\frac{S_{2}}{L_{2}}>\frac{S_{1}}{L_{1}}
$$

that is, there are no factor intensity reversals, with good 2 always being skill intensive.

\subsection{Individual investment behaviour and human capital acquisition}

We assume individuals are heterogeneous with respect to their ability, which is a combination of ordinary and general knowledge that is innate and acquired prior to working age ${ }^{4}$. Individuals are indexed by their ability $(\alpha)$ which for convenience we assume to be uniformly distributed among the population and to vary along the unit interval: $\alpha \in[0,1]$. Each individual's working lifetime is finite and exogenously given by $T$. We suppose that the gross working earnings, per unit of time, of an unskilled worker do not depend on ability and are equal to $W_{L}$. The gross working earnings of a skilled worker depend on the number of efficiency units of skill she possesses and are

\footnotetext{
${ }^{4}$ We can interpret this background period as the compulsory stages of education, for example. 6
} 
equal to $\alpha W_{S}{ }^{5}$. Because skilled workers differ in ability they also differ in earnings. Moreover, the lifetime net earnings of skilled workers differ from their lifetime gross earnings, because of the cost of schooling.

Becoming skilled involves an investment in formal education, an investment which we assume can be undertaken at any time during an individual's working life. Consider an unskilled worker with $\mathrm{t}$ periods experience in the labour market (i.e. whose time to retirement is $\mathrm{T}-\mathrm{t}$ periods). The net present value to this worker of now becoming skilled is the difference between discounted costs and discounted benefits:

$$
R(\alpha, t)=-\int_{0}^{\mathrm{E}}\left[\beta W_{S}+W_{L}\right] e^{-r z} d z+\int_{E}^{T-t}\left[\alpha W_{S}-W_{L}\right] e^{-r z} \mathrm{dz}
$$

where $r$ is the interest rate in a perfect capital market ${ }^{6}$. The higher is $R(\alpha, t)$, the better the investment, and we assume all individuals with positive net returns to schooling will upgrade. Taking derivatives we see that, given a wage structure,

$$
\frac{\partial}{\partial t} R(\alpha, t)=-\frac{\left[\alpha W_{S}-W_{L}\right]}{e^{r[T-t]}}<0 \text { and } \frac{\partial}{\partial \alpha} R(\alpha, t)=\frac{W_{S}}{r}\left[e^{-r E}-e^{-r[T-t]}\right]>0
$$

an individual of given ability with a positive return from education should undertake education as early as possible - i.e. before entering the workforce $(R(\alpha, 0)>R(\alpha, t)$ for $t>0$ ). Equation (5) also indicates that the gains from becoming skilled increase with ability. We can solve $R(\tilde{\alpha}, t)=0$ to find the level of ability $(\tilde{\alpha}(t))$ above which an individual of age $t$ would choose to skill upgrade:

$$
\tilde{\alpha}(t)=\Gamma(t) \beta+[1+\Gamma(t)] w=w+\Gamma(t)[\beta+w]
$$

with $\Gamma(t) \equiv \frac{e^{r T}\left[e^{r E}-1\right]}{e^{r T}-e^{r[E+t]}}$ and $w=\frac{W_{L}}{W_{S}}$. In the steady state, all individuals with $\alpha>\tilde{\alpha}$ $(\equiv \tilde{\alpha}(0))$ will become skilled and individuals with $\alpha \leq \tilde{\alpha}$ will enter the labour market immediately unskilled. As $\Gamma(0)>0, \quad \beta>0$ and $w>0$, the critical level of ability $(\tilde{\alpha})$ is always higher than zero 7 .

5 These assumptions are based on the idea that unskilled work involves standard tasks, while skilled work involves more complex tasks for which training is required and on which the time taken depends on the worker's ability.

${ }^{6}$ Clearly no worker for whom $T-t \leq E$ can benefit from skill upgrading.

${ }^{7}$ Note that if becoming skilled was instantaneous $(E=0), \tilde{\alpha}$ would simply equal the relative wage (as then $\Gamma(0)=0)$. 
Figure 1 - Ability and Gross Earnings

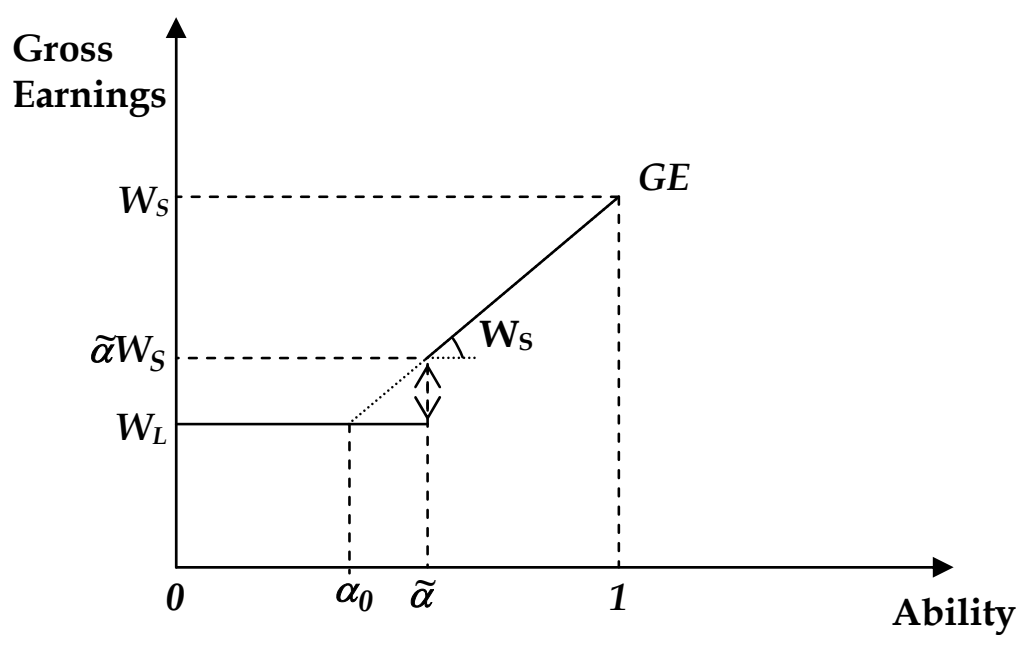

Figure 1 illustrates the relationship between ability level and gross earnings (GE). In equilibrium, individuals with ability in the interval $[0, \tilde{\alpha}]$ do not acquire skills and spend their entire working life earning $W_{L}$ per period. The gross earnings of unskilled workers do not depend on ability level so GE is horizontal in this interval. Individuals with higher ability become skilled and spend their post-educational work life earning $\alpha W_{S}$ per period. Gross earnings of skilled workers depend positively on ability, and vary along the interval $\left[\widetilde{\alpha} W_{S}, W_{S}\right]$, with positive slope $\alpha$. If education were costless, GE would be continuous, and individuals with ability in the interval $\left[\alpha_{0}, \tilde{\alpha}\right]$ would decide to become skilled. But costly education (in either time or resources) implies a decrease in the number of skilled workers and an increase in the average level of ability of the skilled labour force. In the steady state equilibrium those unskilled workers in the range $\left(\alpha_{0}, \tilde{\alpha}\right]$ have a positive skill premium (i.e. $\left.\alpha W_{S}>W_{\mathrm{L}}\right)$, but the present value of this is not sufficient to offset the costs of education. The existence of this group will prove significant when we consider the adjustment process to an anticipated liberalisation below.

\subsection{Factor endowments in the steady-state}

We assume that at each point in time an exogenous number of individuals $(n)$ are born and die. Thus the workforce at any time is equal to $T n=N$. Furthermore, we assume each individual's replacement is identical in terms of ability. Thus, in the steady state $\tilde{\alpha} N$ individuals constitute the supply of unskilled labour. The remaining $[1-\tilde{\alpha}] N$ are 
either skilled $\left([1-\tilde{\alpha}][T-E] n=[1-\tilde{\alpha}]\left[1-\frac{E}{T}\right] N\right)$ or students $\left([1-\tilde{\alpha}] E n=[1-\tilde{\alpha}] \frac{E}{T} N\right)$.

The average level of ability of individuals that decide to become skilled is $[1+\tilde{\alpha}] / 2$. The supplies of unskilled and skilled labour services are then, respectively:

$$
\begin{aligned}
& L=\tilde{\alpha} N \\
& S=\frac{1}{2}[1+\tilde{\alpha}][1-\tilde{\alpha}]\left[1-\frac{E}{T}\right] N=\frac{1}{2}\left[1-\tilde{\alpha}^{2}\right]\left[1-\frac{E}{T}\right] N
\end{aligned}
$$

Not all skilled labour services will be used in the production of goods, since $\beta$ units of skilled labour are allocated to each student. The number of units of skill allocated to education and those available for goods production are then given by

$$
\begin{aligned}
& S_{E}=\beta[1-\tilde{\alpha}] \frac{E}{T} N \\
& S_{M}=S-S_{E}=[1-\tilde{\alpha}]\left[\frac{[1+\tilde{\alpha}]}{2}\left[1-\frac{E}{T}\right]-\beta \frac{E}{T}\right] N
\end{aligned}
$$

\section{An Unanticipated Trade Liberalisation}

In this section we compare the effects of an unanticipated trade liberalisation on factor returns and skill acquisition in a small skilled-labour abundant country 9 . Since world prices are given, the liberalisation changes domestic product and therefore domestic factor prices in accordance with the Stolper-Samuelson theorem. The real return to the abundant factor (skilled labour) will rise (from $W_{S}$ to $W_{S}{ }^{\prime}$ ), and the real return to unskilled labour will fall (from $W_{L}$ to $W_{L}{ }^{\prime}$ ), so that $w^{\prime}<w$. We suppose the liberalisation occurs at time 0 .

\subsection{Skilled workers.}

Consider a skilled worker with $T-t$ periods to retirement. The change in this worker's discounted future income is given by

\footnotetext{
8 The lifetime supply of skilled labour (in efficiency units) of the average skilled worker is $[1+\tilde{\alpha}][T-E] / 2$. The number of units of skilled labour required to educate a skilled worker is $\beta E$. Therefore, when converted to an annual flow, the net supply of skilled labour of the average skilled worker over her working life is $\frac{[1+\tilde{\alpha}]}{2}\left[1-\frac{E}{T}\right]-\beta \frac{E}{T}$.

${ }^{9}$ The outcomes for an unskilled labour abundant country follow analogously and are omitted for brevity. 


$$
G_{S}(\alpha, t)=\int_{0}^{T-t} \alpha\left[W_{S}^{\prime}-W_{S}\right] e^{-r z} d z=\alpha \frac{\left[W_{S}^{\prime}-W_{S}\right]}{r}\left\{\frac{e^{r T}-e^{r t}}{e^{r T}}\right\}>0
$$

All existing skilled workers gain from the liberalisation, but the gains are larger for younger and for more able workers ${ }^{10}$.

\subsection{Students}

The gain to an erstwhile skilled worker still in the student phase $(t \leq E)$ is

$$
\begin{aligned}
G_{E}(\alpha, t) & =-\int_{0}^{E-t} \beta\left[W_{S}^{\prime}-W_{S}\right] e^{-r z} d z+\int_{E-t}^{T-t} \alpha\left[W_{S}^{\prime}-W_{S}\right] e^{-r z} d z \\
& =\frac{G_{S}(\alpha, E)}{e^{r[E-t]}}-\beta \frac{\left[W_{S}^{\prime}-W_{S}\right]}{r}\left[\frac{e^{r[E-t]}-1}{e^{r[E-t]}}\right]
\end{aligned}
$$

Students benefit from an increase in their discounted earnings as skilled workers, but lose through an increase in the direct cost of education. They are net gainers overall, however ${ }^{11}$. The biggest gainers at each ability level are the students on the verge of graduating at the time of liberalisation $(t=E)$.

\subsection{Unskilled workers}

The equivalent comparison for continuing unskilled workers is given by

$$
G_{L}(t)=\int_{0}^{T-t}\left[W_{L}^{\prime}-W_{L}\right] e^{-r z} d z=-\frac{\left[W_{L}-W_{L}^{\prime}\right]}{r}\left\{\frac{e^{r T}-e^{r t}}{e^{r T}}\right\}<0
$$

All such workers lose, and the losses are larger for the younger workers. It is customary to then conclude that all unskilled workers lose as a consequence of liberalisation due to their lower wage. But this does not allow for reversal of the decision to stay unskilled, and skill upgrading will be an attractive alternative for some existing unskilled workers as we now show. Workers differ in age and ability, and it is informative to consider both dimensions.

We begin by considering workers of the same age but different abilities. The new ability cutoff for workers of age $t$ is obtained by rewriting (6) at the new factor prices

10 This income gain can alternatively be viewed as a (human) capital gain or a higher than expected return on education.

${ }^{11}$ Clearly the discounted value of their earnings must have exceeded the discounted direct cost of education at the pre-liberalisation skilled wage, otherwise education would not have been profitable in the first place. The liberalisation has simply increased both earnings and direct education costs in the same proportion. 


$$
\tilde{\alpha}^{\prime}(t)=w^{\prime}+\Gamma(t)\left[w^{\prime}+\beta\right]
$$

All unskilled workers with ability in the range $\tilde{\alpha}-\tilde{\alpha}^{\prime}(t)$ will find that skill upgrading raises their discounted lifetime earnings at the post-liberalisation factor prices. Using (6) we see that

$$
\tilde{\alpha}-\tilde{\alpha}^{\prime}(t)=\left[w-w^{\prime}\right]+\Gamma(0)[w+\beta]-\Gamma(t)\left[w^{\prime}+\beta\right]
$$

which is positive for $t=0$ (i.e. there are always gainers among the new entrants), but declining as $t$ increases and becoming zero once $t$ is sufficiently large ${ }^{12}$. Not all of those who upgrade "gain" from the liberalisation of course ${ }^{13}$. The gain for the upgraders is given by

$$
G_{U}(\alpha, t)=\int_{E}^{T-t}\left[\alpha W_{S}^{\prime}-W_{L}\right] e^{-r z} d z-\int_{0}^{E}\left[\beta W_{S}^{\prime}+W_{L}\right] e^{-r z} d z
$$

By setting $G_{U}(\alpha, t)=0$ we can solve for an ability cutoff at each age level $(\hat{\alpha}(t))$ above which upgrading workers are in fact better off as a result of the liberalisation, obtaining

$$
\hat{\alpha}(t)=\Gamma(t) \beta+[1+\Gamma(t)] \frac{W_{L}}{W_{S}^{\prime}}
$$

It is then straightforward to show that

$$
\widehat{\alpha}(t)-\tilde{\alpha}^{\prime}(t)=\frac{W_{L}-W_{L}^{\prime}}{W_{S}^{\prime}} \Gamma(t)>0
$$

Upgraders in the ability range $\hat{\alpha}(t)-\tilde{\alpha}^{\prime}(t)$ are better off than they would have been had they remained unskilled, but are worse off than if the liberalisation had not occurred. Since $\Gamma(t)$ is increasing in $t$, this range is larger among older workers.

We can do similar calculations of age specific cutoffs for given ability levels. The return to upgrading for a worker of ability $\alpha$ and age $t$ at the time of the liberalisation (time 0 )

${ }^{12} \Gamma(t)=\frac{e^{r T}\left[e^{r E}-1\right]}{\left[e^{r T}-e^{r[E+t]}\right]}$ is increasing in $\mathrm{t}$ and becomes increasingly large as $\mathrm{t}$ approaches $T-E$.

${ }^{13}$ The decision to upgrade is based on a comparison of the discounted net benefits from being skilled with the discounted lifetime income at wage $W_{L}^{\prime}$. The gain depends on a comparison of the same net benefits with the alternative income at the higher wage $W_{L}$. 
is given by rewriting (4) at the new factor prices as $R(\alpha, t ; 0)$. Setting this term to zero, we can solve for the oldest worker of ability level $\alpha$ who finds skill upgrading worthwhile:

$$
t(\alpha)=T-E+\frac{1}{r} \ln [1-\Delta(\alpha)]
$$

where $\quad \Delta(\alpha) \equiv \frac{\left[e^{r E}-1\right]\left[\beta W_{S}^{\prime}+W_{L}^{\prime}\right]}{\alpha W_{S}^{\prime}-W_{L}^{\prime}}=\frac{\tilde{\alpha}^{\prime} W_{S}^{\prime}-W_{L}^{\prime}}{\alpha W_{S}^{\prime}-W_{L}^{\prime}}\left[1-e^{-r[T-E]}\right]$

Here $\Delta(\alpha)$ captures the minimum time spent earning the new skilled premium that is necessary to cover the cost of education. This cost (represented by $\left.\left[e^{r E}-1\right]\left[\beta W_{S}^{\prime}+W_{L}^{\prime}\right]\right)$ is the same for all upgraders, but the skill premium $\left(\alpha W_{S}^{\prime}-W_{L}^{\prime}\right)$ is positively related to the upgrader's ability. More able workers can cover this cost more quickly, and therefore the higher the ability level the older the eldest worker that still finds skill upgrading attractive. Note that $\Delta(\alpha)$ is decreasing in $\alpha$, and that $\Delta\left(\tilde{\alpha}^{\prime}\right)=1-e^{-r[T-E]}$ so that $t\left(\tilde{\alpha}^{\prime}\right)=0$ - i.e. only new entrants upgrade at the new ability threshold. Again not all upgraders gain from the liberalisation. The eldest worker of ability $\alpha$ who does so is aged $\hat{t}(\alpha)$, where

$$
\widehat{t}(\alpha)=T-E+\frac{1}{r} \ln [1-\widehat{\Delta}(\alpha)]
$$

and $\quad \widehat{\Delta}(\alpha) \equiv \frac{\left[e^{r E}-1\right]\left[\beta W_{S}^{\prime}+W_{L}\right]}{\alpha W_{S}^{\prime}-W_{L}}$

here $\widehat{\Delta}(\alpha)$ has an analogous interpretation to $\Delta(\alpha)^{14}$ It is straightforward to establish that $t(\alpha)>\bar{t}(\alpha)^{15}$ - i.e. for each ability level there is a range of older upgraders who are worse off after the liberalisation.

\section{[Figure 2]}

These results are illustrated in Figure 2, where ability is measured on the horizontal axis and time to retirement $(T-t)$ on the vertical. $R(\alpha, t ; 0)=0$ shows combinations of age and ability where skill upgrading breaks even, and $G(\alpha, t ; 0)=0$ the corresponding combinations that imply no gain or loss from the liberalisation. Workers

${ }^{14}$ The (hypothetical) comparison here is between upgrading at the post-liberalisation skilled wage and remaining unskilled at the pre-liberalisation unskilled wage.

${ }^{15}$ Since $\partial \Delta(\alpha) / \partial W_{L}^{\prime}>0$ and $W_{L}>W_{L}^{\prime}$, we have $\widehat{\Delta}(\alpha)>\Delta(\alpha)$ and therefore $1-\widehat{\Delta}(\alpha)<1-\Delta(\alpha)$. Subtracting (13) from (11) then gives $t(\alpha)>\widehat{t}(\alpha)$. 
with characteristics above $R(\alpha, t ; 0)=0$ upgrade; those with characteristics above $G(\alpha, t ; 0)=0$ gain. Figure 2 also illustrates the characteristics of those who upgrade (adjust) but are worse off as a result of the liberalisation. These are the least able upgraders in each age cohort or, equivalently, the oldest upgraders in each ability cohort. Consider, for example, workers aged $\tau$. Those whose ability lies in the range $\tilde{\alpha}-\tilde{\alpha}^{\prime}(\tau)$ will upgrade, but of these only the subgroup $\tilde{\alpha}-\hat{\alpha}(\tau)$ will be better off as a result of the liberalisation. Those with ability less than $\tilde{\alpha}^{\prime}(\tau)$ will remain unskilled.

\subsection{Adjustments in factor supplies}

Liberalisation leads to a fall in the ability threshold and thus an increase in the number of skilled workers and a fall in the number of unskilled workers. The new long run equilibrium supply of skilled and unskilled labour can be determined by replacing $\tilde{\alpha}$ with $\tilde{\alpha}^{\prime}$ in (7A) to (7D). The changes in the relevant supplies are

$$
\begin{aligned}
& L^{\prime}-L=\left(\tilde{\alpha}^{\prime}-\tilde{\alpha}\right) N<0 \\
& S^{\prime}-S=\left(\tilde{\alpha}-\tilde{\alpha}^{\prime}\right)\left[\frac{\left(\tilde{\alpha}+\tilde{\alpha}^{\prime}\right)}{2}\left(1-\frac{E}{T}\right)\right] N>0
\end{aligned}
$$

But with more students and the same number of teachers per student, more units of skill are diverted to education - i.e.

$$
S_{E}^{\prime}-S_{E}=\left(\tilde{\alpha}-\tilde{\alpha}^{\prime}\right) \frac{\beta E}{T} N>0
$$

The change in the supply of skilled labour available for traded goods is then ${ }^{16}$ :

$$
S_{M}^{\prime}-S_{M}=\left[\tilde{\alpha}-\tilde{\alpha}^{\prime}\right]\left[\left[\frac{\tilde{\alpha}+\tilde{\alpha}^{\prime}}{2}\right]\left[1-\frac{E}{T}\right]-\frac{\beta E}{T}\right] N>0
$$

These are the changes that take place in the long run. The medium run dynamics, on the other hand, reflect the adjustment of the workforce existing at the time of the liberalisation and its progression towards retirement. This is depicted in Figure 3.

\section{[Figure 3]}

Immediately after liberalisation (time 0) the number of unskilled workers decreases as an increased number of entrants and some of the existing workforce decide to upgrade.

${ }^{16}$ Note that $\left[\frac{\tilde{\alpha}+\tilde{\alpha}^{\prime}}{2}\right]\left[1-\frac{E}{T}\right]-\beta \frac{E}{T}$ is the net skilled labour supply of the average marginal skilled worker from the two long run equilibria. 
While the stock of skilled labour is unaffected, this increase in the number of students increases the skilled labour services drawn into the education system, leaving fewer skilled labour services available for use in the production of traded goods. Thus the medium term impact of the liberalisation will be a fall in traded goods output as both the skilled and unskilled labour supplies available for traded goods production fall. From Figure 2 we can see that as time passes the unskilled labour supply converges towards its new long run equilibrium level, but it remains above this level until the retirement of the last of the age cohorts present at the time of the liberalisation. For the periods from 0 to $t(\tilde{\alpha})$, the number of unskilled workers in the retiring cohorts exceeds that in the entering by $\left[\tilde{\alpha}-\tilde{\alpha}^{\prime}\right] N$. In later periods the retiring cohort includes increasing numbers of workers who upgraded immediately after the liberalisation. But the full adjustment process will take T periods.

The skilled labour supply remains unchanged until E periods after the liberalisation. During this time the number of students and therefore the number of staff in the education sector continues to grow, further reducing the skilled labour available for traded goods production. However, after E periods the skilled labour force is swollen by the graduation of the relatively large batch of post-liberalisation upgraders. They will be supplemented by any staff released from the education sector. From then on the skilled labour force converges to its long run level which it attains at $\mathrm{T}+\mathrm{E}^{17}$.

The long run effects on the composition of trade goods production follows from the Rybczynski Theorem - output of the relatively skilled-labour intensive good increases and output of the other good falls. This is consistent with the findings of FK and Borsook, and models of variable factor supplies in a H-O-S setting (e.g. Martin, 1976; Neary, 1978, Woodland, 1982). What is new here is the result immediately following liberalisation. Both $L$ and $S_{M}$ fall, which will tend to reduce both traded outputs, but may have negative Rybczynski effect depending on the changes in relative factor supplies. However, once the existing upgraders have made their way through the

17 The employment of skilled labour in the education sector in the new steady state may be less than its peak during the adjustment process if the number of unskilled workers upgrading immediately after the liberalisation exceeds the increase in student numbers in the steady state (i.e. $\left[\tilde{\alpha}-\tilde{\alpha}^{\prime}\right] E N / T$ ) 
education system, there will be a progressive shift in outputs towards their long run levels.

\section{An Announced Liberalisation}

We now consider skill upgrading where the government announces (at time 0 ) a trade liberalisation that will take place at a known point in the future $\left(t_{0}\right)$. Agents accord this full credibility and we suppose that the prevailing wage rates after the liberalisation are as in the previous section. Since this liberalisation will raise the return to becoming skilled, some unskilled workers will choose to upgrade. Our objective in this section is to determine: (a) which agents working unskilled at the time of the announcement will choose to upgrade and when; and (b) as time passes and the liberalisation comes closer, how the pattern of upgrading amongst new entrants adjusts to the new steady state.

\subsection{Upgrading strategies}

We begin by looking at the timing of the upgrading decision for current unskilled workers. They have three alternative strategies available: (1) upgrade immediately; (2) upgrade just prior to the liberalisation (so as to be able to take advantage of the higher skilled wage as soon as it is available); or (3) upgrade immediately after the liberalisation. The corresponding income streams for an agent of ability $\alpha$ and age $t$ at the time of the announcement are, respectively:

$$
\begin{aligned}
& I_{1}\left(\alpha, t ; t_{0}\right)=-\int_{0}^{E} \beta W_{S} e^{-r z} d z+\int_{E}^{t_{0}} \alpha W_{S} e^{-r z} d z+\int_{t_{0}}^{T-t} \alpha W_{S}^{\prime} e^{-r z} d z \\
& I_{2}\left(\alpha, t ; t_{0}\right)=\int_{0}^{t_{0}-E} W_{L} e^{-r z} d z-\int_{t_{0}-E}^{t_{0}} \beta W_{S} e^{-r z} d z+\int_{t_{0}}^{T-t} \alpha W_{S}^{\prime} e^{-r z} d z \\
& I_{3}\left(\alpha, t ; t_{0}\right)=\int_{0}^{t_{0}} W_{L} e^{-r z} d z-\int_{t_{0}}^{t_{0}+E} \beta W_{S}^{\prime} e^{-r z} d z+\int_{t_{0}+E}^{T-t} \alpha W_{S}^{\prime} e^{-r z} d z
\end{aligned}
$$

We can establish ranges of ability over which each alternative will be preferred. Note that $t$ affects each of these flows in exactly the same way. The period of earning the post-liberalisation skilled wage is shorter the older the worker at the time of the announcement. So as long as all three are viable for a given agent, her preferences over them will be independent of her age.

The agent's preferences between upgrading immediately or just prior to the 
liberalisation will be determined by

$$
\begin{aligned}
I_{1}-I_{2} & =-\int_{0}^{E}\left[W_{L}+\beta W_{S}\right] e^{-r z} d z+\int_{E}^{t_{0}-E}\left[\alpha W_{S}-W_{L}\right] e^{-r z} d z+\int_{t_{0}-E}^{t_{0}}\left[\alpha W_{S}+\beta W_{S}\right] e^{-r z} d z \\
& =\frac{\left[e^{r t_{0}}-e^{r E}\right]}{r e^{r t_{0}}}\left\{\frac{[\alpha+\beta] W_{S}}{e^{r E}}-\left[W_{L}+\beta W_{S}\right]\right\}
\end{aligned}
$$

Note that $t_{0}>E$ for the distinction between these options to be meaningful, and that (16) is increasing in $\alpha$. The difference between the two strategies is clear. If the agent upgrades immediately the opportunity cost (relative to continuing to work as unskilled and upgrading later) is $W_{L}$, and then the agent's earnings depend on their ability and the current skilled wage. If the agent upgrades later, the cost of education is deferred but their earnings in the meantime are the current unskilled wage and the opportunity cost of upgrading is their foregone skilled earnings $\left(\alpha W_{S}\right)$. The agent indifferent between these two alternatives has ability $\alpha_{12}$ where

$$
\alpha_{12} W_{S}-W_{L}=\left[e^{r E}-1\right]\left[\beta W_{S}+W_{L}\right]
$$

One can show that $\tilde{\alpha}>\alpha_{12}>\alpha_{0}$, so that an agent on the margin of becoming skilled under the pre-liberalisation regime will prefer $I_{1}$ to $I_{2}$ once the liberalisation is announced. An agent who would earn the same whether skilled or unskilled under the pre-liberalisation factor prices (i.e. an agent of ability $\alpha_{0}$ ) would prefer to defer the cost of education.

The agent's preferences between upgrading just before and just after the liberalisation are given by:

$$
\begin{aligned}
I_{2}-I_{3} & =-\int_{t_{0}-E}^{t_{0}}\left[W_{L}+\beta W_{S}\right] e^{-r z} d z+\int_{t_{0}}^{t_{0}+E}\left[\alpha W_{S}^{\prime}+\beta W_{S}^{\prime}\right] e^{-r z} d z \\
& =\frac{\left[e^{r E}-1\right]}{r e^{r t_{0}}}\left\{\frac{[\alpha+\beta] W_{S}^{\prime}}{e^{r E}}-\left[W_{L}+\beta W_{S}\right]\right\}
\end{aligned}
$$

Again this comes down to a comparison of discounted education costs. The advantage of delayed upgrading is that these costs are further in the future. The disadvantage is that both the direct cost and the opportunity cost (i.e. working as skilled under the new wage structure) are higher. The agent indifferent between these two alternatives has ability $\alpha_{23}$ where 


$$
\left[\alpha_{23}+\beta\right] W_{S}^{\prime}=e^{r E}\left[\beta W_{S}+W_{L}\right]
$$

One can show that $\alpha_{12}>\alpha_{23}$. Since both (16) and (18) are increasing in $\alpha$, we have established that $I_{1}$ is the preferred option for upgraders in the ability range $\tilde{\alpha}>\alpha \geq \alpha_{12}, I_{2}$ is the preferred option for upgraders in the ability range $\alpha_{12}>\alpha \geq \alpha_{23}$, and $I_{3}$ is the preferred option for upgraders in the ability range $\alpha_{23}>\alpha>\tilde{\alpha}^{\prime}$.

We noted that these cutoffs are independent of the worker's age. Equations (17) and (19) reveal that they are also independent of the proximity of the liberalisation $\left(t_{0}\right)$. Further, we see from (17) that the cutoff between strategies $I_{1}$ and $I_{2}$ is independent of the size of the liberalisation, and hence independent of the new steady state threshold ability. Thus if we compare

$$
\tilde{\alpha}-\alpha_{12}=\frac{e^{r E}\left[e^{r E}-1\right]}{\left[e^{r T}-e^{r E}\right]} \frac{\left[\beta W_{S}+W_{L}\right]}{W_{S}} \text { and } \quad \tilde{\alpha}-\tilde{\alpha}^{\prime}=\frac{e^{r E}\left[e^{r T}-1\right]}{\left[e^{r T}-e^{r E}\right]}\left[\frac{W_{L}}{W_{S}}-\frac{W_{L}^{\prime}}{W_{S}^{\prime}}\right]
$$

We can see that $\tilde{\alpha}^{\prime}>\alpha_{12}$ if the liberalisation is sufficiently small - i.e. if

$$
\frac{\left[e^{r E}-1\right]}{\left[e^{r T}-1\right]} \frac{\left[\beta W_{S}+W_{L}\right]}{W_{S}}>\left[\frac{W_{L}}{W_{S}}-\frac{W_{L}^{\prime}}{W_{S}^{\prime}}\right]
$$

In this case all upgraders among the existing workforce would prefer to do so immediately the liberalisation is announced. In contrast from (19) we see that the cutoff between strategies $I_{2}$ and $I_{3}$ is influenced by the size of the liberalisation. A larger liberalisation implies that both $\tilde{\alpha}^{\prime}$ and $\alpha_{23}$ are smaller, the latter because the (direct and opportunity) cost of education is higher under strategy $I_{3}$. Again it is possible that $\tilde{\alpha}^{\prime}>\alpha_{23}$, this time if

$$
\frac{\left[\beta W_{S}^{\prime}+W_{L}^{\prime}\right]}{\left[\beta W_{S}+W_{L}\right]}>\frac{\left[e^{r T}-e^{r E}\right]}{\left[e^{r T}-1\right]}
$$

In this case all upgraders among the existing workforce would prefer to upgrade before the liberalisation occurs. Note that the right side of this inequality is less than unity, which implies that if the cost of becoming skilled is higher post-liberalisation, then all upgrading will occur prior to the liberalisation. 


\subsection{Returns to upgrading}

Having established their preferred options should they choose to upgrade, we now consider the returns from skill upgrading for each group. These will depend on worker age. For a given size and proximity of liberalisation we wish to determine for each ability cohort, the maximum age for which an existing worker will find skill upgrading profitable. Clearly under options $I_{1}$ and $I_{2}$ this must be bounded by $T-t_{0}$, since workers of this age or older will have left the labour force before the liberalisation occurs. For option $I_{3}$ the bound is $T-t_{0}-E$ since the worker would not complete schooling until $E$ periods after the liberalisation. The returns to skill upgrading under the three options for a worker of ability $\alpha$ and age $t$, when a liberalisation occurs $t_{0}$ periods in the future are given by, respectively:

$$
\begin{aligned}
& R_{1}\left(\alpha, t ; t_{0}\right)=-\int_{0}^{E}\left[\beta W_{S}+W_{L}\right] e^{-r z} d z+\int_{E}^{t_{0}}\left[\alpha W_{S}-W_{L}\right] e^{-r z} d z+\int_{t_{0}}^{T-t}\left[\alpha W_{S}^{\prime}-W_{L}^{\prime}\right] e^{-r z} d z \\
& R_{2}\left(\alpha, t ; t_{0}\right)=-\int_{t_{0}-E}^{t_{0}}\left[\beta W_{S}+W_{L}\right] e^{-r z} d z+\int_{t_{0}}^{T-t}\left[\alpha W_{S}^{\prime}-W_{L}^{\prime}\right] e^{-r z} d z \\
& R_{3}\left(\alpha, t ; t_{0}\right)=-\int_{t_{0}}^{t_{0}+E}\left[\beta W_{S}^{\prime}+W_{L}^{\prime}\right] e^{-r z} d z+\int_{t_{0}+E}^{T-t}\left[\alpha W_{S}^{\prime}-W_{L}^{\prime}\right] e^{-r z} d z
\end{aligned}
$$

It is clear that $R_{j}\left(\alpha, t ; t_{0}\right), j=1,2,3$ is lower the older a worker of given ability ${ }^{18}$. If we set $R_{j}\left(\alpha, t ; t_{0}\right)=0$, we can solve for the maximum age $\left(t_{j}\left(\alpha ; t_{0}\right)\right)$ at which a worker of ability $\alpha$ would find upgrading worthwhile under option $\mathrm{j}$. These solutions are given by

$$
t_{j}\left(\alpha ; t_{0}\right)=T-t_{0}+\frac{1}{r} \ln \left[1-\Delta_{j}(\alpha)\right] \quad(j=1,2) ; t_{j}\left(\alpha ; t_{0}\right)=T-t_{0}-E+\frac{1}{r} \ln \left[1-\Delta_{3}(\alpha)\right]
$$

where

$$
\Delta_{1}(\alpha)=\frac{e^{r t_{0}}\left[e^{r E}-1\right]\left[\beta W_{S}+W_{L}\right]-\left[e^{r t_{0}}-e^{r E}\right]\left[\alpha W_{S}-W_{L}\right]}{e^{r E}\left[\alpha W_{S}^{\prime}-W_{L}^{\prime}\right]}
$$

$$
\Delta_{2}(\alpha)=\frac{\left[e^{r E}-1\right]\left[\beta W_{S}+W_{L}\right]}{\alpha W_{S}^{\prime}-W_{L}^{\prime}} ; \quad \Delta_{3}(\alpha)=\frac{\left[e^{r E}-1\right]\left[\beta W_{S}^{\prime}+W_{L}^{\prime}\right]}{\alpha W_{S}^{\prime}-W_{L}^{\prime}}
$$

${ }^{18}$ Since $\frac{\partial R_{j}(\alpha, t)}{\partial e^{r t}}=-\frac{\left[\alpha W_{S}^{\prime}-W_{L}^{\prime}\right]}{r} e^{-r T}<0$ in each case. 
The interpretations of $\Delta_{2}(\alpha)$ and $\Delta_{3}(\alpha)$ are straightforward - they represent the minimum time spent working at the new skill premium necessary to offset the cost of upgrading. A similar interpretation applies to $\Delta_{1}(\alpha)$, once one takes into account that these upgraders had a period spent earning a positive skill premium prior to the liberalisation. $\Delta_{1}(\alpha)$ represents the minimum time spent earning the new skill premium that is required to offset the total costs of education that are not covered by earnings at the old skill premium ${ }^{19}$. Inspection reveals that $\partial \Delta_{j}(\alpha) / \partial \alpha<0$ and therefore $\partial t_{j}(\alpha) / \partial \alpha>0$ within each range, and it is straightforward to show that the solutions to (22) have $t_{1}(\tilde{\alpha})>t_{1}\left(\alpha_{12}\right)=t_{2}\left(\alpha_{12}\right)>t_{2}\left(\alpha_{23}\right)=t_{3}\left(\alpha_{23}\right)$. We would expect to observe a decline in the age of the oldest worker upgrading as we consider workers of lower ability. Of course $t_{j}(\alpha)=0$ will occur at some point in the range $\left[\tilde{\alpha}, \tilde{\alpha}^{\prime}\right]$, depending on the proximity of the liberalisation and its size. No current workers of lower ability will then upgrade.

These outcomes are illustrated in Figure 4. The pre-liberalisation steady state ability cutoff is given by $\tilde{\alpha}$ and the post-liberalisation steady state cutoff by $\tilde{\alpha}^{\prime}$. We assume that the liberalisation is sufficiently large that some existing workers will prefer each of the three upgrading strategies, at least when the liberalisation is sufficiently proximate. In this figure each $R_{j}\left(\alpha, t ; t_{0}\right)=0$ is negatively sloped since both ability and youth raise the return to skill upgrading. Further, we can show that, for any common $(\alpha, T-t)$, $R_{j}$ is steeper than $R_{j+1}$ - i.e. ${ }^{20}$

${ }^{19}$ The costs of education and earnings from the old skill premium (both discounted to time 0 ) are respectively $\left[1-e^{-r E}\right]\left[\beta W_{S}+W_{L}\right]$ and $\left[e^{-r E}-e^{-r t_{0}}\right]\left[\alpha W_{S}-W_{L}\right]$. If we subtract the second from the first and then multiply the outcome by $e^{r t_{0}}$, we have the "education cost deficit" at the time of the liberalisation. If we then divide this by the new skill premium $\left[\alpha W_{S}^{\prime}-W_{L}^{\prime}\right]$, we have the minimum time necessary earning the new skill premium to offset this deficit. $\Delta_{1}(\alpha)$ is simply a rearrangement of this term.

${ }^{20}$ As noted above a change in $T$ - $t$ has the same effect on returns under all three strategies $\partial R_{j} / \partial[T-t]=\left[\alpha W_{S}^{\prime}-W_{L}^{\prime}\right] / e^{-r[T-t]}>0, j=1,2,3$. The difference lies in the effects of a change in ability. A higher ability increases the return under strategy $I_{1}$ through a higher skill premium both before and after the liberalisation. The former effect is absent from the other strategies. The discounted post-liberalisation skill premium is the same under strategies $I_{1}$ and $I_{2}$, and 19 


$$
\left|\frac{\partial[T-t]}{\partial \alpha}\right|_{R_{1}}>\left|\frac{\partial[T-t]}{\partial \alpha}\right|_{R_{2}}>\left|\frac{\partial[T-t]}{\partial \alpha}\right|_{R_{3}}
$$

The more proximate the liberalisation the longer the period spent earning the new skill premium and hence the higher the return to skill upgrading at any ability-age combination. This implies that the $R_{j}\left(\alpha, t ; t_{0}\right)=0$ schedules shift down as $t_{0}$ falls, maintaining their points of intersection at the crossover abilities established above.

The announcement of a liberalisation that would not take place during the working life of the existing labour force (i.e. $t_{0} \geq T$ ) will induce no upgrading by them. However, any $t_{0}$ such that $T>t_{0} \geq 0$ will induce upgrading by some workers, as illustrated by the shaded area in Figure 4. As noted above, those workers in this area with ability in the range $\tilde{\alpha} \geq \alpha>\alpha_{12}$ will upgrade immediately the announcement is made, those in the range $\alpha_{12} \geq \alpha>\alpha_{23}$ will plan to upgrade just before the liberalisation occurs, and those in the range $\alpha_{23} \geq \alpha>\alpha_{3}\left(t_{0}\right)$ just after. The worker of lowest ability who plans to upgrade is a new entrant $(T-t=T)$ with ability

$$
\alpha_{3}\left(t_{0}\right)=\tilde{\alpha}^{\prime}+\left[\frac{\tilde{\alpha}^{\prime} W_{S}^{\prime}-W_{L}^{\prime}}{W_{S}^{\prime}}\right]\left[\frac{e^{r\left[t_{0}+E\right]}-e^{r E}}{e^{r T}-e^{r\left[t_{0}+E\right]}}\right] \geq \tilde{\alpha}^{\prime}
$$

The oldest worker who upgrades does so immediately and has ability $\tilde{\alpha}$ and from (22) age

$t_{1}\left(\tilde{\alpha} ; t_{0}\right)=T-t_{0}+\frac{1}{r} \ln \left[1-\Delta_{1}\left(\tilde{\alpha} ; t_{0}\right)\right]<T-t_{0}$ and $\Delta_{1}\left(\tilde{\alpha} ; t_{0}\right)=\frac{\left[\tilde{\alpha} W_{S}-W_{L}\right]}{\left[\tilde{\alpha} W_{S}^{\prime}-W_{L}^{\prime}\right]} \frac{e^{r T}-e^{r t_{0}}}{e^{r T}}$

The larger and more proximate the liberalisation the older the eldest worker who upgrades (i.e. $t_{1}\left(\tilde{\alpha} ; t_{0}\right)$ converges towards $T-t_{0}$ from above as the liberalisation becomes larger).

However, once $t_{0}=E$ strategies $I_{1}$ and $I_{2}$ become identical. An even more proximate liberalisation $\left(t_{0}<E\right)$ means that upgrading cannot be completed before it occurs, and

smaller under strategy $I_{3}$ because the period during which it is earned is shorter due to upgrading being undertaken after the liberalisation. Thus

$$
\begin{aligned}
& \partial R_{2} / \partial \alpha=-\left[W_{S}^{\prime} / r\right]\left[e^{-r[T-t]}-e^{-r t_{0}}\right]>0 ; \quad \partial R_{3} / \partial \alpha=-\left[W_{S}^{\prime} / r\right]\left[e^{-r[T-t]}-e^{-r\left[t_{0}+E\right]}\right]>0 ; \quad \text { and } \\
& \partial R_{1} / \partial \alpha=\partial R_{2} / \partial \alpha-\left[W_{S} / r\right]\left[e^{-r t_{0}}-e^{-r E}\right]>\partial R_{2} / \partial \alpha .
\end{aligned}
$$


the only strategies available are $I_{3}$ and hybrids of $I_{1}$ (equivalently $I_{2}$ ) and $I_{3}$. Clearly for an immediate liberalisation only $I_{3}$ is available, in which case $\alpha_{3}(0)=\tilde{\alpha}^{\prime}$. At the other end of the ability range $(\tilde{\alpha})$, it is straightforward to compare the oldest worker who upgrades (under strategy $I_{1}$ ) when $t_{0}=E$, with the oldest worker who upgrades (under strategy $I_{3}$ ) when $t_{0}=0$. In each case the relevant worker begins skill upgrading immediately and enters the labour market as a skilled worker E periods later. The difference between the two is that in the former case education is incurred at the old factor prices while in the latter case it is incurred at the new. Education is more costly post-liberalisation if $\beta\left[W_{S}^{\prime}-W_{S}\right]>\left[W_{L}-W_{L}^{\prime}\right]$ in which case $t_{1}(\tilde{\alpha} ; E)>t_{3}(\tilde{\alpha} ; 0)$.

But like an unannounced liberalisation, not all upgraders are better off than they would have been if the liberalisation did not take place. The gain from liberalisation under upgrading strategy $\mathrm{j}$ can be determined from

$$
G_{j}\left(\alpha, t ; t_{0}\right)=I_{j}\left(\alpha, t ; t_{0}\right)-I_{0}(t), \quad \text { where } I_{0}(t)=\int_{0}^{T-t} W_{L} e^{-r z} d z
$$

Here $I_{0}(t)$ represents the (hypothetical) income that would have been earned had the liberalisation not taken place. It is then straightforward to show that the difference between the gain from liberalisation and the return to upgrading is the same across the three upgrading strategies - i.e.

$$
G_{j}\left(\alpha, t ; t_{0}\right)-R_{j}\left(\alpha, t ; t_{0}\right)=\frac{\left[W_{L}^{\prime}-W_{L}\right]}{r}\left[\frac{e^{r[T-t]}-e^{r t_{0}}}{e^{r[T-t]} e^{r t_{0}}}\right]<0
$$

Since this involves a comparison as an unskilled worker at the pre- and postliberalisation wages it is independent of ability. The gain is always less than the return, implying that, at each ability level, the marginal upgrader is worse off as a result of the liberalisation. The older the worker or the less proximate the liberalisation, the smaller the difference. The oldest worker who gains at each ability level can be determined in the same way as the oldest worker who upgrades, by solving $G_{j}\left(\alpha, t ; t_{0}\right)=0$ for $\widehat{t}_{j}\left(\alpha ; t_{0}\right)$. The solutions are as given by (22) and (23) above, if $\alpha W_{S}^{\prime}-W_{L}^{\prime}$ is replaced by the smaller quantity $\alpha W_{S}^{\prime}-W_{L}$. 


\subsection{Adjustments to factor supplies}

The dynamic pattern of upgrading from the time of announcement to the date of liberalisation is shown in Figure 5. To heighten the contrast with an unanticipated liberalisation we consider the announcement of a large liberalisation (so that $\tilde{\alpha}^{\prime}<\alpha_{23}$ ) to take place far in the future (i.e. at time $\tau \approx T$ ). Then few of the current workforce will upgrade, and those that do will be young workers choosing strategy $I_{1}$. As time passes older unskilled workers retire and the liberalisation becomes more proximate. While this does not affect further those in the workforce at the time of the announcement who have already made their upgrading plans, it does affect subsequent new entrants. Let $\tilde{\alpha}^{\prime}(0)$ denote the ability of the least able entrant who decides to upgrade. As long as $\tilde{\alpha}^{\prime}(0)>\alpha_{12}$ all entrant upgrading will take place immediately on entry, and we have a steady decline in the number of unskilled workers as retirees are not fully replaced by new entrants. Once $\alpha_{23}<\tilde{\alpha}^{\prime}(0)<\alpha_{12}$ any additional new entrants who plan to upgrade will do so just before the liberalisation. The supply of unskilled entrants is thus stable and remains so even when $\tilde{\alpha}^{\prime}(0)<\alpha_{23}$, as the expanding range of entrants who aim to upgrade plan to do so immediately after the liberalisation. Once we reach $\tau-E$, those who plan to upgrade under strategy $I_{2}$ cease working as unskilled and enter the education system. This is followed by a further drop when the liberalisation occurs (at time $\tau$ ), corresponding to those following strategy $I_{3}$. The unskilled labour force reaches its new long run equilibrium when the all the workforce at the time of the announcement have retired (i.e. T periods after the announcement). The increases in the total supply of skilled labour are the mirror image of these adjustments in the supply of unskilled labour once they have made their way through the education system (i.e. with an E period lag).

\section{Reversals and Regrets}

The preceding sections have considered the effects of anticipated and unanticipated liberalisations. If the liberalisations are of the same size, they will yield identical steady state equilibria, although the transition paths will be different as we have seen. In this section we return to an unanticipated liberalisation in a skilled-labour abundant country to compare the outcomes with those that would have occurred had 
the existing workforce known that the liberalisation was to take place when it did at the time they entered the labour force. Our aim is to identify those workers with "regrets", particularly those who would have upgraded had they anticipated the liberalisation, but who do not find upgrading worthwhile after an unanticipated liberalisation. Of course these are not the only workers with regrets, since some of those who still upgrade would have done so earlier had they anticipated the liberalisation.

Consider any worker of age $t$ in the labour force at the time that the unanticipated liberalisation occurs. Had this worker known, at the time she entered the labour force, when the liberalisation was going to occur, she would have had the three options for the timing of upgrading discussed in the previous section. Determining the worker's preferred option involves the same comparisons as in the previous section (if we set $t_{0}=t$ and $\left.t=0\right)$. Thus the preference depends only on the worker's ability. Those for whom $\tilde{\alpha} \geq \alpha>\alpha_{12}$ would have upgraded immediately on entering the workforce; those for whom $\alpha_{12} \geq \alpha>\alpha_{23}$ would have entered unskilled but upgraded immediately before the liberalisation; and those for whom $\alpha_{23} \geq \alpha>\tilde{\alpha}^{\prime}$ would have entered unskilled and only upgraded once the liberalisation had occurred. Clearly the latter group can have no regrets since their preferred action is the same whether the liberalisation is anticipated or not.

We have derived the return from upgrading for anticipated and unanticipated liberalisations in the previous sections. In each case the return is increasing in ability but declining in age. For each ability level therefore we can solve for the oldest worker (at the time of the liberalisation) who would have found it worthwhile to upgrade for an anticipated liberalisation and compare this with the oldest worker who finds upgrading profitable after an unanticipated liberalisation of the same size. For the former this involves solving $R_{j}(\alpha, 0 ; t)=0$ for $t_{j}(\alpha)$, which is straightforward for strategies $I_{2}$ and $I_{3}$ but less so for $I_{1}$ as now ' $\mathrm{t}$ ', which represents both the worker's age and the time at which the liberalisation takes place, determines the division of working time spent earning at the old and the new skill premia. The solution is most readily interpretable if we rewrite $R_{1}(\alpha, 0 ; t)$ as 


$$
\begin{aligned}
R_{1}(\alpha, 0 ; t)=-\int_{0}^{E} & {\left[\beta W_{S}+W_{L}\right] e^{-r z} d z+\int_{E}^{T}\left[\alpha W_{S}-W_{L}\right] e^{-r z} d z } \\
& +\int_{t}^{T}\left\{\left[\alpha W_{S}^{\prime}-W_{L}^{\prime}\right]-\left[\alpha W_{S}-W_{L}\right]\right\} e^{-r z} d z
\end{aligned}
$$

The first two terms on the right of (26) represent the net return from upgrading at the pre-liberalisation factor returns. We know that this is negative for $\alpha<\tilde{\alpha}$. The final term in (26) is the additional income from the higher skill premium post-liberalisation, and depends on $t$, the age of the worker when the liberalisation occurs. The oldest worker who upgrades under strategy $I_{1}$ is determined where the final term offsets the first two. We therefore have

$$
t_{1}(\alpha)=T-\frac{1}{r} \ln \left[1+\Delta_{1}^{R}(\alpha)\right], \quad t_{2}(\alpha)=T+\frac{1}{r} \ln \left[1-\Delta_{2}^{R}(\alpha)\right] ; t_{3}(\alpha)=T-E+\frac{1}{r} \ln \left[1-\Delta_{3}^{R}(\alpha)\right]
$$

Where $\Delta_{2}^{R}(\alpha)$ and $\Delta_{3}^{R}(\alpha)$ are as defined in (23) above and

$$
\Delta_{1}^{R}(\alpha)=\frac{e^{r[T-E]}\left[e^{r E}-1\right]\left[\beta W_{S}+W_{L}\right]-\left[e^{r[T-E]}-1\right]\left[\alpha W_{S}-W_{L}\right]}{\left[\alpha W_{S}^{\prime}-W_{L}^{\prime}\right]-\left[\alpha W_{S}-W_{L}\right]}
$$

Here $\Delta_{1}^{R}(\alpha)$ reflects the minimum time required earning the increase in the skill premium to offset the deficit in the return to skill upgrading at the old factor prices. The comparison with an unanticipated liberalisation is facilitated by noting that $e^{-r t} R_{3}(\alpha, 0 ; t)=R_{3}(\alpha, t ; 0)$, so that when these are equated to zero the oldest worker who finds it profitable to upgrade under strategy $I_{3}$ after an anticipated liberalisation is the same as the oldest worker who finds it profitable to upgrade after an unanticipated liberalisation at this ability level. Note that each $\Delta_{j}^{R}(\alpha)$ is decreasing in $\alpha$, and that it is straightforward to show that $\Delta_{1}^{R}(\tilde{\alpha})=0$, so that $t_{1}(\tilde{\alpha})=T$ - i.e. all workers at the old ability threshold would have upgraded had they anticipated the liberalisation; $1-\Delta_{3}^{R}\left(\tilde{\alpha}^{\prime}\right)=e^{-r[T-E]}$, so that $t_{3}\left(\tilde{\alpha}^{\prime}\right)=0$ - i.e. at the new ability threshold, only new entrants at the time of the liberalisation will upgrade; $t_{1}\left(\alpha_{12}\right)=t_{2}\left(\alpha_{12}\right)$ and $t_{2}\left(\alpha_{23}\right)=t_{3}\left(\alpha_{23}\right)$. The comparison of upgrades under anticipated and unanticipated liberalisations is shown in Figure 6.

\section{[Figure 6]}

If the timing and size of the liberalisation are fully known to entrants at the time they enter then those whose ability and working age at the time of the liberalisation places 
them above the $\min \left\{R_{j}(\alpha, 0 ; t)=0, j=1,3\right\}$ boundary will upgrade at the optimal time. If the liberalisation is not anticipated, then only those workers whose ability and working age at the time of the liberalisation place them above the $R_{3}(\alpha, 0 ; t)=0$ boundary will upgrade. This implies that workers in the ability range [ $\tilde{\alpha}$ to $\left.\tilde{\alpha}^{\prime}\right]$ can be divided into four categories: (a) those who choose to remain unskilled whether they anticipate the liberalisation or not; (b) those for whom $I_{3}$ is the preferred strategy anyway and hence are indifferent between an anticipated and an unanticipated liberalisation; (c) those who upgrade in each case, but would prefer to use either strategy $I_{1}$ or $I_{2}$ for an anticipated liberalisation - these workers regret and reverse their decision to remain unskilled if an unanticipated liberalisation occurs; and (d) those who would have upgraded under strategies $I_{1}$ or $I_{2}$ if they had anticipated the liberalisation and who regret but do not reverse the decision to remain unskilled for an unanticipated liberalisation. These workers tend to be older than those in (c). The location of each of these groups is indicated in Figure 6. The regrets by some unskilled workers who remain unskilled, and by others that they had not upgraded earlier, indicates that policy changes can impose psychological costs on some agents. These are not adjustment costs of the policy change, but may be important for its reception and the political economy of its long run success.

\section{Adjustment Assistance}

In this section we briefly consider some issues in the design and implementation of a program of "adjustment assistance" intended to compensate those workers who are not net gainers from the liberalisation and who undertake costly adjustment. Obviously this is not, and is not intended to be, a general model of adjustment to trade liberalisation. Along with skill upgrading, trade liberalisation in this model involves the reallocation of workers between sectors, which we have assumed to take place instantaneously and costlessly. This is of course unrealistic, but is a necessary simplification if we are to focus on the medium run adjustment through skills upgrading. Furthermore, there is no efficiency argument for the provision of adjustment assistance in this model. All workers are fully informed and make the optimal choices. Our aim is not to provide a detailed analysis of the costs and benefits of adjustment assistance. Rather we wish to use this model as a vehicle to illustrate the 
difficulties of designing an adjustment scheme that only compensates the losers ${ }^{21}$.

Governments do not provide specific schemes of redistribution of the gains from trade. Some redistribution may happen indirectly, through general taxation of the gainers and social welfare payments to the losers (should their losses consign them to the social safety net). But in the context of our model we would not expect the government to make any specific attempt to redistribute from existing skilled workers who all gain to continuing unskilled workers who all lose. Where special assistance may be provided is to those who undertake costly adjustment as a result of the liberalisation. In this model these are the members of the existing workforce who choose to upgrade. The general assumption underlying such programmes is that worker adjustment that occurs in response to trade policy changes is involuntary and represents a cost imposed on a reluctant worker. As we have seen this is not necessarily the case.

\subsection{An unanticipated liberalisation}

Consider first the case of an unanticipated liberalisation. Then, as discussed in section 3, those workers whose return from upgrading is now positive will undertake it. Not all these workers are better off as a result of the liberalisation, however, and in each ability cohort the younger upgraders gain and the older upgraders lose. But because the gains from upgrading are increasing in ability and decreasing in age, the age cutoff between those who gain and those who lose is increasing in ability. If both worker characteristics were observable, then a scheme could be designed that only compensated the losers. But while age is likely to be observable, ability is not ex ante. Nor would it be revealed by a worker's unskilled income, which is assumed to be independent of ability. Any scheme based on age alone is likely to fail to capture some losers with low ability while rewarding some gainers of higher ability.

\subsection{An anticipated liberalisation}

When we turn to an announced liberalisation, it is apparent that the assistance scheme itself can introduce a distortion into the economy. Typically assistance is only provided to members of the existing workforce adjusting after the liberalisation has occurred. But,

${ }^{21}$ Ichida (2005) provides a careful and detailed discussion of the difficulties in designing compensation schemes to redistribute the gains from trade through product and factor taxes and subsidies. 
as we saw in section 4, for an announced liberalisation it is optimal for much of the upgrading to take place before the liberalisation. Those upgraders following strategies $I_{1}$ and $I_{2}$ will be ineligible for adjustment assistance, although these groups will contain (older) workers who are net losers from the liberalisation. The presence of adjustment assistance that is restricted to strategy $I_{3}$ then distorts the timing of upgrading as we now show. Since our objective is primarily illustrative, we restrict attention to the simplest case where (a) the full costs of upgrading (i.e. $\beta W_{S}^{\prime}$ and $W_{L}^{\prime}$ ) are reimbursed to those members of the existing workforce who choose to upgrade after the liberalisation, and (b) the liberalisation itself is trivially small so that factor returns are unaffected. Clearly this is an extreme case, but we can rely on continuity to infer that similar outcomes will occur for significant education subsidies and a small liberalisation.

We begin by noting that an unanticipated liberalisation under this regime would see upgrading by all existing workers with ability $\alpha_{0}<\alpha<\alpha^{\prime}$ (where $\alpha_{0} W_{S}=W_{L}$ ) and age $t<T-E$. Those with ability above the threshold will already have upgraded. Clearly, there will be some socially inefficient upgrading among the existing workforce. Now consider the announcement at time 0 of a (trivial) liberalisation to take place at time $t_{0}$, with full compensation of post-liberalisation adjustment costs. Since there will be no change in factor returns, the liberalisation itself generates no upgrading - i.e. there is no change in the steady state ability threshold. What will induce changes in upgrading behaviour is the education subsidy. At the time of the announcement all existing workers whose ability was above the threshold had either upgraded (if $t>E$ ) or were undertaking schooling (if $t \leq E$ ). Those in schooling, and any subsequent entrants prior to the liberalisation have to decide whether to (continue to) upgrade now, paying the full cost, or to wait until after the liberalisation and upgrade for free. Consider the choice of a worker just entering the labour force at the time of the announcement. For this worker the benefits of upgrading immediately rather than at $t_{0}$ are given by

$$
I M\left(\alpha, 0 ; t_{0}\right)=-\int_{0}^{E}\left[\beta W_{s}+W_{L}\right] e^{-r z} d z+\int_{E}^{t_{0}+E}\left[\alpha W_{s}-W_{L}\right] e^{-r z} d z
$$

The negative term is the costs of education and the positive term the benefits of earning the skill premium earlier. The entrant who is indifferent between the two strategies has 
ability $\alpha_{A}$, where

$$
\frac{\alpha_{A} W_{S}-W_{L}}{\tilde{\alpha} W_{S}-W_{L}}=\frac{e^{r t_{0}}\left[e^{r[T-E]}-1\right]}{e^{r[T-E]}\left[e^{r t_{0}}-1\right]}
$$

This implies that $\alpha_{A} \geq \tilde{\alpha}$ as $t_{0} \leq T-E$. Some new entrants who would otherwise have upgraded immediately will delay upgrading until after the liberalisation, as long as it is not so distant into the future that they would have no time working as a skilled worker. An anticipated future liberalisation accompanied by a program of adjustment assistance that compensates for upgrading costs undertaken after the liberalisation, may lead to reductions in the numbers in schooling and a consequent increase in the unskilled workforce, prior to the liberalisation.

\section{Conclusions}

Our aim in this paper has been to highlight how the characteristics of the existing workforce, particularly the age and ability of unskilled workers, affects when and whether they opt for skill upgrading in response to a trade liberalisation. To this end we adapted the models of FK and Borsook to focus on medium term adjustments by the existing workforce. The conventional view is that trade liberalisation in a relatively skill abundant country makes all skilled workers better off and all unskilled workers worse off. Treating each occupational group as homogeneous ignores differences within them and, most significantly the possibility of mobility between groups.

Because trade liberalisation in a relatively skill abundant country increases the relative return to skilled labour, it induces some skill upgrading by existing unskilled workers. An unanticipated liberalisation will induce those close to the old ability threshold to upgrade. Because the return on upgrading is increasing in ability and decreasing in age, younger, more able workers are more likely to upgrade and older, less able workers to remain unskilled. While all upgraders become skilled as a result of the liberalisation, not all are better off than before. Specifically, for any given ability cohort the youngest workers upgrade and gain, an intermediate range upgrade but lose and the oldest remain unskilled (and lose). The balance among these three groups shifts towards the losers as we consider lower ability cohorts. These results confirm the widespread view that older workers are more likely to lose among the adjusters to trade liberalisation. 
A similar pattern applies for an announced trade liberalisation. The most significant difference is that the announcement allows the option of upgrading prior to the liberalisation and this option will be preferred by those closest to the pre-liberalisation ability threshold and hence those most likely to upgrade. The implication is that if a liberalisation is anticipated, much of the adjustment - or indeed all of it if the liberalisation is small enough - will take place prior to the liberalisation itself. This has implications for both the empirical measurement of adjustment and the design of programs of adjustment assistance. Neither of these should be restricted to the postliberalisation period.

The attitudes of workers to an unanticipated liberalisation will be influenced not only by its consequences for their incomes but also by what might have been. Using the results from anticipated and unanticipated liberalisations, we are able to identify those workers who would have upgraded prior to the liberalisation had they known it was coming when the entered the labour force, and to divide them into those who still upgrade and those who do not. Both subgroups regret the decision to remain unskilled but only the first reverse it. Again the composition of these groups depend on worker characteristics. Regardless of age, more able unskilled workers are more likely to upgrade prior to the liberalisation. For any ability cohort older workers are less likely to reverse their entry decision to remain unskilled.

Whether it is anticipated or not any adjustment to a trade liberalisation via upgrading is a dynamic process that may take much longer than suggested by conventional analysis. The new factor returns imply a lower skilled labour ability threshold, and, although all existing unskilled workers could reverse their decision to remain unskilled, for older or less able workers it will not be attractive to do so. Until the new steady state is achieved (i.e. as long as the workforce contains individuals who entered prior to the liberalisation or its announcement), the supply of skilled (unskilled) labour in a skill-abundant country will be below (above) its long run level.

While in no way intending to offer a detailed analysis of adjustment assistance, our results suggest two important considerations for the design of such a program. First, some upgraders (adjusters) are gainers and some losers from trade liberalisation. There would seem to be little argument for compensating the former. Second, if 
liberalisation is anticipated, some adjustment optimally will occur before the liberalisation. Hence a program of adjustment assistance that provides subsidies of adjustment costs, but only after the liberalisation has occurred, will distort the timing of adjustment away from its optimal path.

There are several directions in which this work might usefully be extended in the future. The integration of short run adjustment costs would allow a more comprehensive consideration of adjustment assistance. Not all upgrading occurs via a formal schooling process. On-the-job training is an important alternative form of skill acquisition, often for skills that are firm or industry specific. Investigation of the effects of trade liberalisation on the demand for and supply of these types of skills requires a different model. The range of skills relevant to the labour market and the different channels through which they can be acquired (from formal schooling to experience) make empirical investigation difficult. Further complexity is added by potential capital market distortions and the extensive role of governments in the financing and provision of training. But the growing availability of matched worker-firm data sets suggests some progress will soon be possible. 


\section{REFERENCES}

Becker, G. (1993), “Human capital a theoretical and empirical analysis with special reference to education", University of Chicago Press, Chicago.

Becker, G. S. (1964), “Human Capital.”, Columbia University Press, New York for the National Bureau of Economic Research.

Becker, G. S. and Chiswick, B. R. (1966), "Education and the Distribution of Earnings", American Economic Review, Proceedings, vol. 56, 358-369.

Borsook, I. (1986), “Earnings, Ability and International Trade”, Journal of International Economics, vol. 22, 281-295.

Davidson, C. and S. Matusz (?)

Dinopoulos, E. and P. Segerstrom (1999) “A Schumpeterian Model of Protection and Relative Wages", American Economic Review, vol 89(3), 450-72.

Findlay, R. and Kierzkowski, H. (1983), “International Trade and Human Capital: A Simple General Equilibrium Model", Journal of Political Economy, vol. 91(6), 957978.

Ichida, T. (2005) “Occupational Choice and Compensation for Losers from International Trade", Waseda University.

Martin, J. (1976), “Variable Factor Supplies and The Heckscher-Ohlin-Samuelsom Model", The Economic Journal, vol. 86, 820-831.

Matusz, S. and Tarr D. (2002), "Adjusting to Trade Policy Reform" in Anne Krueger (Eds.): Economic Policy Reform: The Second Stage, University of Chicago Press, 365-399.

Mincer, J. (1974), “Schooling, Experience, and Earnings”, NBER Press, New York.

Mincer, J. (1993), “Collected essays of Jacob Mincer”, Edward Elgar, Aldershot.

Neary, J. (1978), “Capital Subsidies and Employment in an Open Economy”, Oxford Economic Papers, vol. 30, 334-356.

Woodland, A. (1982), "International Trade and Resource Allocation”, North-Holland, Amsterdam. 


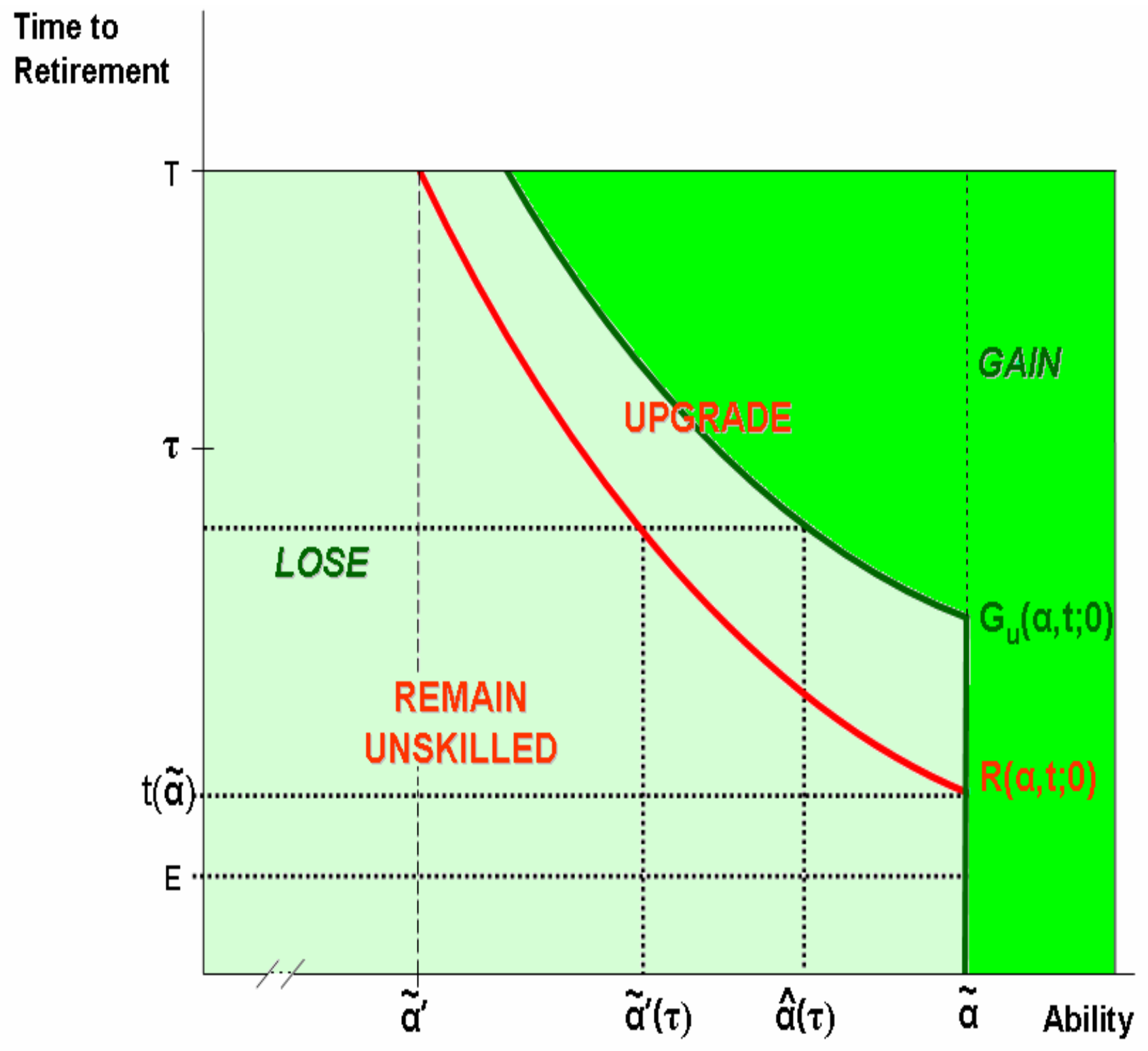

Figure 2 Ugraders, Gainers and Losers under an Unannounced Trade Liberalisation 


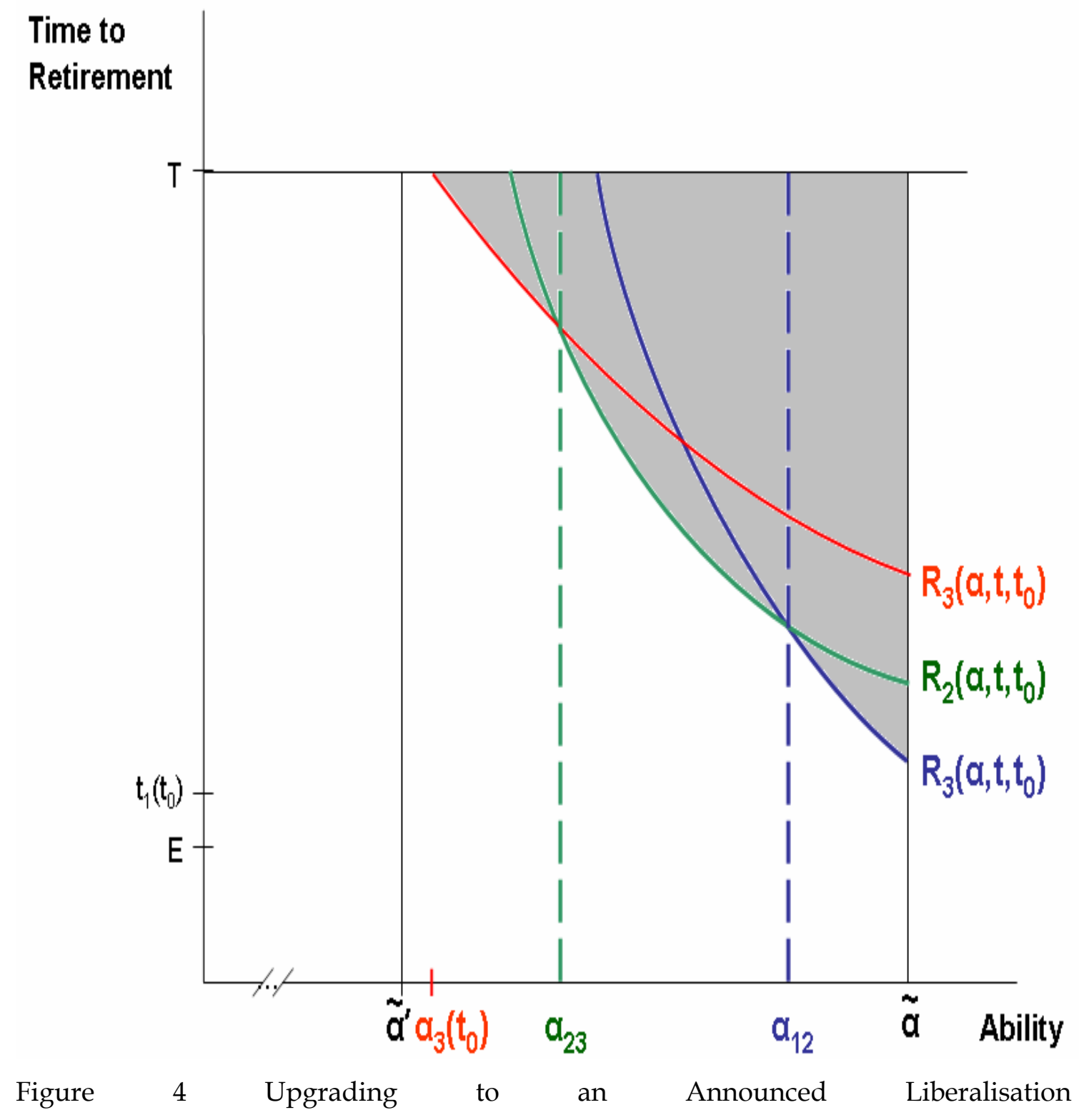


Time to

Retirement

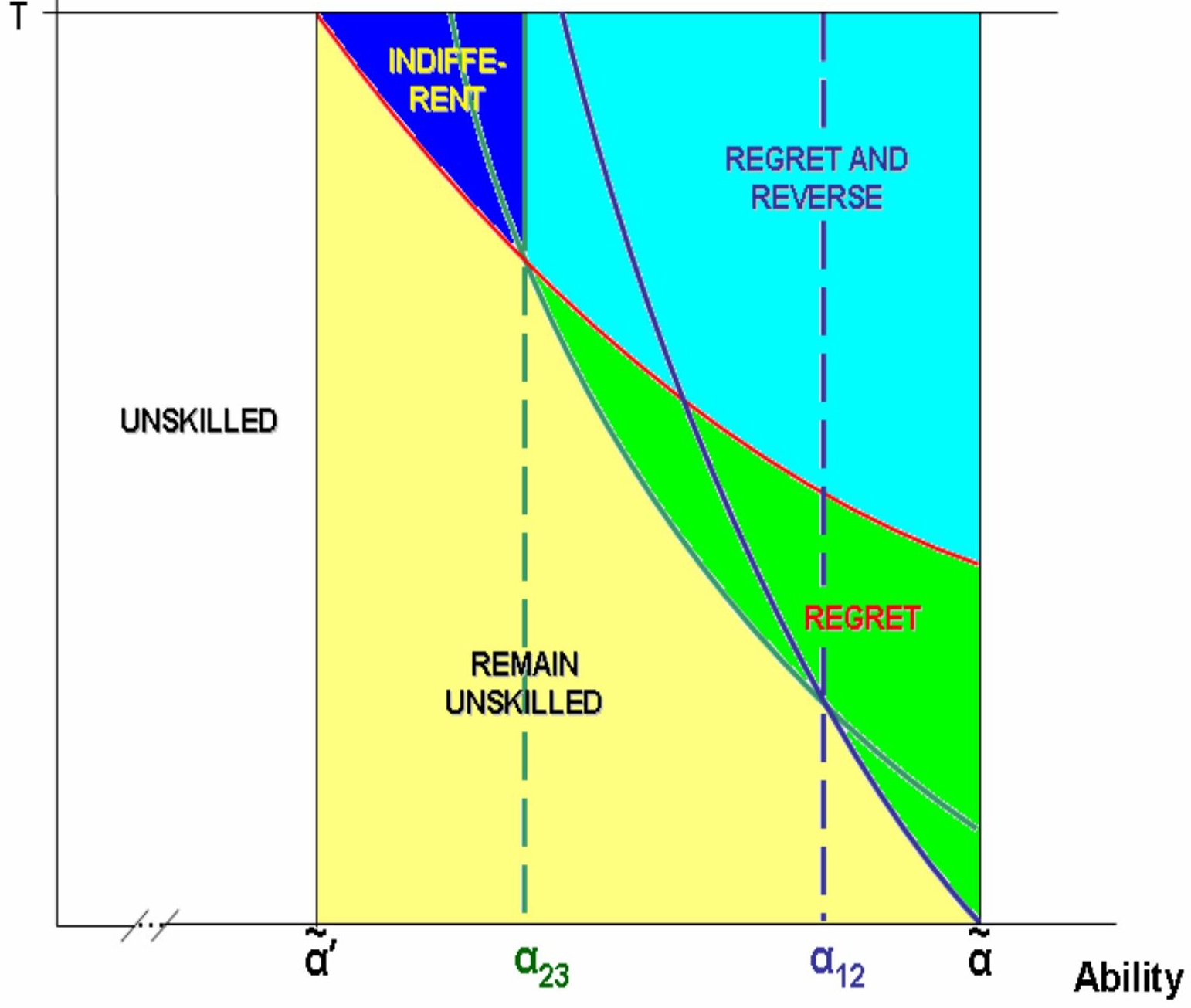

Figure 5

Regrets and Reversals 